\title{
The generalist's dilemma: training and staying current in the face of increasing specialization
}

\author{
David H Henry, MD, FACP
}

$\mathrm{S}$

o, let me ask you a question: How do you stay up-todate in oncology and hematology? In particular, are you at an academic institution or in community practice? Do you do only oncology, or is your focus oncology and hematology? If you are in an academic institution, you probably are highly specialized in one tumor type. If your practice is in a community setting, you probably treat a range of cancer types as well as hematology. Throw into this mix the fact that new therapies and new indications for existing drugs are being approved, and that guidelines are routinely updated, and you realize the tremendous pressure you're under to stay current, whether you're a specialist or a generalist.

If you practice at an academic center and are highly specialized, you probably go to the annual meeting of the American

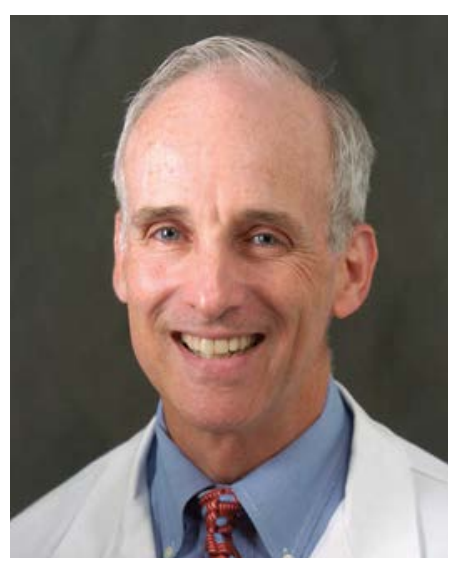

and educated, but in some respects they may end up doing two fellowships. If they go into community practice where all tumor types, with or without hematology, are seen, the first few years of their first attending job may effectively be a "second fellowship" as they learn how to manage patients across a range of tumor types.

Personally, I still attend ASCO and ASH and even try to go to those societies' regional review sessions but doing so takes time away from home and is not inexpensive. I find the ASH and National Comprehensive Cancer Network guidelines invaluable as up-to-date, quick reference resources to review the latest guidelines in oncology and hematology. I round out those sources with online webcasts or podcasts, and some journal reading. And then in addition to the allimportant patient-time, there is time-conSociety of Clinical Oncology (ASCO) each year and attend only the sessions of your subspecialty. You probably also go to subspecialty meetings such as the San Antonio Breast Cancer Symposium or the American Society of Hematology (ASH), or those for any of the other subspecialities. Then there is the community practice-based oncologist, and I wonder to what extent ASCO and/or ASH are meeting their needs. Yes, there are educational sessions, but they are becoming increasingly specialized, as are oral and poster presentations. The Community Oncology Alliance, a nonprofit organization that advocates for community oncology, says that fewer of its members attend the bigger meetings these days because of this trend toward specialty. I must emphasize, however, that I have found the ASCO and ASH regional review sessions that occur after the major meetings to be particularly helpful for those of us who are in broad tumor-type community oncology practices.

What about the residents and fellows - how are we training them? There is increasing pressure for our fellows in training to focus on one tumor type and remain with a single mentor who has an interest in that particular tumor type. Our fellows are certainly very well trained suming electronic medical record keeping, which takes a lot more time these days. Finally, I remember to do something else called Family Time and to participate in other nonmedical interests, perhaps to relax on weekends when I am not on call.

What a busy life we have chosen, and it is becoming increasingly difficult and time consuming to stay current. So, how do you stay up-to-date? We'd like to know, so please visit our website, www.jcso-online.com, and respond to the poll on our homepage. We'd love to hear from you!

One of the most important ways of learning and keeping abreast of current trends is through contact and exchange with our colleagues. We hope that The Journal of Community and Supportive Oncology serves as such a platform for our readers. This month, we feature 2 original reports that focus on practice in the community setting and we hope will be of use to you in your practice: on page 173, Patt and colleagues report on the use of nab-paclitaxel for treating patients with human epidermal growth factor receptor 2-negative metastatic breast cancer, and Del Fabbro and colleagues (p. 181) report on attitudes toward detecting and managing cancerrelated anorexia-cachexia syndrome. 